\title{
Infarct Patterns, Collaterals and Likely Causative Mechanisms of Stroke in Symptomatic Intracranial Atherosclerosis
}

\author{
Elena López-Cancio ${ }^{a}$ Maria Gisele Matheus ${ }^{b}$ Jose G. Romano ${ }^{d}$ \\ David S. Liebeskind ${ }^{\mathrm{e}}$ Shyam Prabhakaran ${ }^{f}$ Tanya N. Turan ${ }^{c}$ \\ George A. Cotsonis ${ }^{g}$ Michael J. Lynn ${ }^{g}$ Zoran Rumboldt ${ }^{b}$ \\ Marc I. Chimowitz ${ }^{c}$ on behalf of the Warfarin-Aspirin Symptomatic Intracranial \\ Disease (WASID) trial investigators

\begin{abstract}
${ }^{a}$ Department of Neurosciences, Germans Trias i Pujol University Hospital, Badalona, Spain; Departments of
${ }^{\mathrm{b}}$ Radiology and ' Neurosciences, Medical University of South Carolina, Charleston, S.C., 'Cerebrovascular Division,

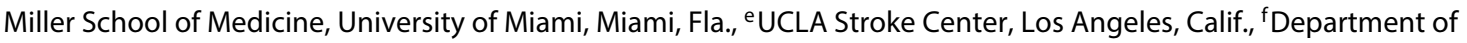
Neurology, Northwestern University-Feinberg School of Medicine, Chicago, Ill., and ${ }^{9}$ Department of Biostatistics, Emory University, Atlanta, Ga., USA
\end{abstract}

\section{Key Words}

Infarct patterns · Intracranial atherosclerotic stenosis ·

Collaterals · Stenosis location · Warfarin-Aspirin

Symptomatic Intracranial Disease study

\begin{abstract}
Background: There are limited data on the specific mechanisms of stroke in patients with intracranial atherosclerotic stenosis (ICAS). We undertook this study to describe infarct patterns and likely mechanisms of stroke in a large cohort of patients with ICAS, and to evaluate the relationship of these infarct patterns to angiographic features (collaterals, stenosis location and stenosis severity). Methods: We evaluated infarct patterns in the territory of a stenotic intracranial artery on neuroimaging performed at baseline and during follow-up if a recurrent stroke occurred in patients enrolled in the Warfarin-Aspirin Symptomatic Intracranial Disease
\end{abstract}

(WASID) trial. We defined the likely mechanism of stroke (artery-to-artery embolism, perforator occlusion, hypoperfusion or mixed) according to the site of ICAS and based on the infarct patterns on neuroimaging. Collaterals were assessed using American Society of Interventional and Therapeutic Neuroradiology/Society of Interventional Radiology (ASITN/ SIR) grades, and stenosis severity using the WASID trial's measurement technique. We evaluated the association of infarct patterns with angiographic features using $X^{2}$ tests. Results: The likely mechanisms of stroke based on the infarct patterns at baseline in the 136 patients included in the study were artery-to-artery embolism ( $n=69 ; 50.7 \%$ ), perforator occlusion ( $n=34 ; 25 \%)$, hypoperfusion $(n=12 ; 8.8 \%)$ and mixed ( $n=21 ; 15.5 \%$ ). Perforator-occlusive infarcts were

See the online supplementary file for a list of WASID trial investigators.

\section{KARGER}

E-Mail karger@karger.com

www.karger.com/ced
(C) 2014 S. Karger AG, Basel

1015-9770/14/0376-0417\$39.50/0
Dr. Elena López-Cancio

Departamento de Neurociencias, Secretaría $7^{\mathrm{a}}$ planta

Hospital Universitario Germans Trias i Pujol, Carretera del Canyet s/n

ES-08916 Badalona, Barcelona (Spain)

E-Mail elenacancio@gmail.com 
more frequent in the posterior circulation, and mixed patterns were more prevalent in the anterior circulation (both $p<0.01)$. Most of the mixed patterns in the anterior circulation combined small pial or scattered multiple cortical infarcts with infarcts in border-zone regions, especially the cortical ones. Isolated border-zone infarcts were not significantly associated with a poor grading for collaterals or the severity of stenosis. Among 47 patients with a recurrent infarct during follow-up, the infarct patterns suggested an artery-to-artery embolic mechanism in 29 (61.7\%). Conclusions: Artery-to-artery embolism is probably the most common mechanism of stroke in both the anterior and the posterior circulations in patients with ICAS. An extension of intracranial atherosclerosis at the site of stenosis into adjacent perforators also appears to be a common mechanism of stroke, particularly in the posterior circulation, whereas hypoperfusion as the sole mechanism is relatively uncommon. Further research is important to accurately establish the specific mechanisms of stroke in patients with ICAS, since preliminary data suggest that the underlying mechanism of stroke is an important determinant of prognosis.

(c) 2014 S. Karger AG, Basel

\section{Introduction}

Possible mechanisms of stroke associated with largeartery intracranial atherosclerotic stenosis (ICAS) include artery-to-artery embolism, hypoperfusion, branch occlusive disease and a combination of these mechanisms [1-3]. Establishing the specific mechanism of stroke in individual patients and the overall frequency of each mechanism in ICAS patients is potentially important because different mechanisms of stroke could be associated with different prognoses and responses to medical or endovascular treatment [4-6].

One way to try to establish mechanisms of stroke is to use infarct patterns on brain imaging to infer the underlying stroke mechanism. Previous studies have done this in patients without ICAS [5, 7-11], but there is a paucity of data on this subject in patients with ICAS. Additionally, there are limited data on the association between infarct patterns and angiographic features such as collateral circulation and severity of stenosis.

We undertook this study to describe infarct patterns and likely mechanisms of stroke, as well as the association between infarct patterns and angiographic features, in a large cohort of patients with ICAS enrolled in the Warfarin-Aspirin Symptomatic Intracranial Disease (WASID) trial.

\section{Patients and Methods}

Study Design and Subjects

The WASID trial was a double-blind randomized prospective multicenter trial conducted at 59 sites in North America to compare aspirin with warfarin for preventing stroke in patients with symptomatic ICAS [12]. Details on the design of this trial and the baseline characteristics of the patients included have been published previously $[12,13]$. All 569 patients enrolled in the WASID trial had a transient ischemic attack or nondisabling stroke within 90 days prior to enrollment that was attributable to angiographically verified $50-99 \%$ stenosis of a major intracranial artery (carotid, middle cerebral, vertebral or basilar). Patients with tandem extracranial stenosis and a cardiac source of embolism were excluded.

We included two overlapping groups of patients from the WASID trial for the present study: group 1 consisted of 136 patients who had an infarct in the territory of the stenotic artery on brain imaging as the qualifying event and who had complete angiographic information on the state of collaterals in the anterior and posterior circulation (flow chart in online suppl. fig. 1; for all online suppl. material, see www.karger.com/doi/10.1159/000362922), and group 2 comprised 47 patients who had a recurrent infarct in the territory of the stenotic artery confirmed by brain imaging during the follow-up of the trial (flow chart in online suppl. fig. 2).

\section{Angiographic Data}

All conventional angiograms that qualified patients for the WASID trial were centrally adjudicated for the degree of arterial luminal narrowing according to the WASID measurement technique [14]. Stenoses were classified as moderate $(50-69 \%)$ or severe (70-99\%). Evaluations of the collateral circulation were performed by one of the coauthors (D.S.L.) [15]. Collaterals were assessed with the American Society of Interventional and Therapeutic Neuroradiology (ASITN)/Society of Interventional Radiology (SIR) collateral flow grading system [16]. This system categorizes collaterals into 5 grades ( $0-4$ ) varying from 0 (no collaterals visible) to 4 (complete and rapid collateral blood flow to the territory distal to the stenosis). For this analysis, the collaterals were categorized as absent (grade 0 ), poor (grades 1 and 2) or good (grades 3 and 4). All angiographic readings were conducted blinded to the results of the neuroimaging and patient outcomes.

\section{Infarct Patterns on Neuroimaging and Likely Mechanisms of} Stroke

All brain CT and MRI studies were reviewed by two investigators (E.L.-C. and M.G.M.) blinded to the clinical and angiographic data. A third reader's (M.I.C.) opinion was sought in cases of disagreement. The topography of the ischemic infarcts by vascular territories was determined with reference to published templates $[17,18]$.

The infarct patterns were classified as follows:

(1) Perforator pattern - subcortical lesions in the distribution of perforating vessels that originate at the site of stenosis

(2) Territorial pattern -1 or more lesions located distal to the stenotic vessel (cortical, subcortical or both) that are restricted to the territory supplied by a single intracranial artery

(3) Border-zone pattern - 1 or more lesions in the internal (corona radiata or centrum semiovale) and/or the cortical border-zone region (between the middle cerebral artery and the anterior ce- 
Table 1. Baseline infarct patterns and angiographic features

\begin{tabular}{|c|c|c|c|c|c|}
\hline & Perforator & Territorial $^{\mathrm{a}}$ & Border zone & Mixed & $\mathrm{p}^{\mathrm{b}}$ \\
\hline Stenosis severity & & & & & 0.65 \\
\hline $50-70 \%(\mathrm{n}=74)$ & $18(24.3 \%)$ & $35(47.3 \%)$ & $8(10.8 \%)$ & $13(17.6 \%)$ & \\
\hline$\geq 70 \%(\mathrm{n}=62)$ & $16(25.8 \%)$ & $34(54.8 \%)$ & $4(6.4 \%)$ & $8(13 \%)$ & \\
\hline Collaterals - ASITN/SIR grade & & & & & 0.56 \\
\hline None $-0(n=82)$ & $22(26.8 \%)$ & $42(51.2 \%)$ & $5(6.1 \%)$ & $13(15.9 \%)$ & \\
\hline Poor -1 or $2(n=35)$ & $7(20 \%)$ & $18(51.4 \%)$ & $5(14.3 \%)$ & $5(14.3 \%)$ & \\
\hline Good -3 or $4(n=19)$ & $5(26.3 \%)$ & $9(47.4 \%)$ & $2(10.5 \%)$ & $3(15.8 \%)$ & \\
\hline Stenosis location & & & & & $<0.01$ \\
\hline $\operatorname{ICA}(n=20)$ & $1(5 \%)$ & $13(65 \%)$ & $1(5 \%)$ & $5(25 \%)$ & \\
\hline $\operatorname{MCA}(n=47)$ & $9(19.1 \%)$ & $17(36.2 \%)$ & $11(23.4 \%)$ & $10(21.3 \%)$ & \\
\hline $\mathrm{VA}(\mathrm{n}=29)$ & $7(24.1 \%)$ & $22(75.9 \%)$ & 0 & 0 & \\
\hline $\mathrm{BA}(\mathrm{n}=29)$ & $13(44.8 \%)$ & $12(41.4 \%)$ & 0 & $4(13.8 \%)$ & \\
\hline Tandem $(\mathrm{n}=11)$ & $4(36.4 \%)$ & $5(45.4 \%)$ & 0 & $2(18.2 \%)$ & \\
\hline
\end{tabular}

Percentages of each stroke pattern according to each angiographic category are given in parentheses. ICA = Internal carotid artery; $\mathrm{VA}=$ vertebral artery; BA = basilar artery; tandem = ICA + MCA or VA + BA concomitant stenoses.

a Artery-to-artery embolism.

${ }^{\mathrm{b}} \chi^{2}$ test for comparisons between any of the subgroups.

rebral artery or the middle cerebral artery and the posterior cerebral artery)

(4) Mixed pattern - a combination of any of the previous patterns We defined the likely mechanism of stroke related to ICAS as follows: perforator occlusion for a perforator pattern, artery-toartery embolism for a territorial pattern, hypoperfusion for a border-zone pattern and a mixed mechanism for a mixed pattern of infarct.

\section{Results}

Patterns of Baseline Infarcts and Association with Angiographic Features

The neuroimaging studies used to evaluate the $136 \mathrm{pa}-$ tients with baseline infarcts ( 72 in the posterior circulation and 64 in the anterior circulation) were CT in 14 cases, diffusion-weighted imaging (DWI) MRI in 89 cases and FLAIR MRI in 33 cases. The following infarct patterns were found in these 136 patients: territorial $(\mathrm{n}=69$; $50.7 \%)$, perforator $(\mathrm{n}=34 ; 25 \%)$, border zone $(\mathrm{n}=12$; $8.8 \%)$ and mixed $(\mathrm{n}=21 ; 15.5 \%)$. The most frequent infarct pattern in both the anterior and the posterior circulation was territorial (artery-to-artery embolism; fig. 1). Perforator-occlusive infarcts were more frequent in the posterior circulation, and mixed patterns were more prevalent in the anterior circulation (both $\mathrm{p}<0.01$; fig. 1). All isolated border-zone patterns in the anterior circulation $(n=12)$ involved the internal border-zone region, and in

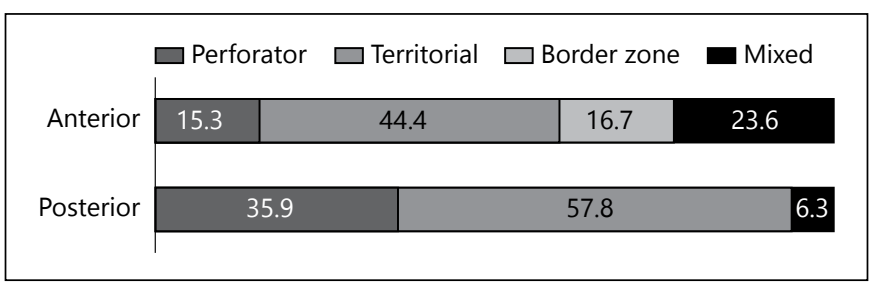

Fig. 1. Prevalence of each infarct pattern in the anterior and the posterior circulations in percent.

7 of them, the cortical border-zone regions (anterior or posterior) were also affected. Most of the mixed patterns in the anterior circulation $(14 / 17 ; 82.3 \%)$ combined small pial or scattered multiple cortical infarcts with infarcts in the border-zone regions, especially the cortical ones.

The analyses correlating stroke patterns with angiographic features showed no statistically significant differences between the infarct patterns with regard to the severity of stenosis or collateral patterns (table 1). Of note, border-zone infarcts were not associated with a poor grading for collaterals or severe stenosis. Regarding the location of stenosis, the border-zone pattern occurred more frequently with middle cerebral artery (MCA) stenosis $(23.4 \%)$ than with ICAS (5\%), and the territorial pattern (artery-to-artery embolism) occurred more frequently with vertebral $(75.9 \%)$ than with basilar artery stenosis (41.4\%; table 1). 


\section{Infarct Patterns and Likely Mechanisms of Recurrent} Stroke

Of the 569 patients enrolled in the WASID trial, 77 had a recurrent stroke in the territory during a mean followup of 1.8 years. Of these patients, 47 had a definite recurrent infarct in the territory on available images, 26 in the anterior circulation and 21 in the posterior circulation. Of these 47 patients, 8 did not have an infarct on baseline imaging (the qualifying event was either a TIA or imaging-negative stroke). Based on our a priori rules as defined above, the mechanisms of recurrent stroke in the 47 patients were artery-to-artery embolism in 29 (61.7\%), perforator occlusion in $11(23.4 \%)$, hypoperfusion in 2 $(4.2 \%)$ and mixed in 5 patients (10.7\%). Among the 39 patients with both baseline and follow-up infarcts on neuroimaging, the majority of patients with an embolicappearing infarct on follow-up imaging also had had an embolic pattern at baseline (75\%). Of the 47 patients with a recurrent infarct in the territory, 26 underwent followup vascular imaging, which showed that the intracranial stenosis had progressed to occlusion in only 5 patients. In these 5 patients, the pattern of the recurrent stroke on brain imaging suggested an embolic mechanism in 4 cases and a mixed pattern in 1 case.

\section{Discussion}

Although there are multiple possible mechanisms of stroke in patients with ICAS, the infarct patterns on brain imaging in this study strongly suggest that artery-to-artery embolism is the most common. Ulceration, plaque rupture or shear stress from high-grade stenosis likely induces platelet-fibrin deposition, which may embolize downstream to distal vessels. Microembolic signals detected by transcranial Doppler that can be associated with multiple infarcts on DWI sequences support this hypothesis [2]. Additionally, other reports have shown that multiple acute infarcts, especially small scattered ones, are frequently related to large-artery atherosclerosis, presumably from artery-to-artery embolism $[3,7,10,19,20]$.

The risk of recurrent stroke in the WASID trial was virtually the same whether patients were on warfarin or on aspirin, suggesting that neither was particularly effective in preventing the most common mechanism of stroke, i.e. artery-to-artery embolism. However, the recently published final results of SAMMPRIS [21] are encouraging in this respect, since the risk of recurrent stroke in the medical arm, both at 30 days and 1 year, was approximately half of that for the WASID trial patients who fulfilled en- trance criteria similar to those of the SAMMPRIS patients. This suggests that high-dose statins, better blood pressure control and the combination of aspirin and clopidogrel may be effective in lowering the risk of artery-to-artery embolism in ICAS patients. Indeed, combination antiplatelet therapy has been shown to decrease microemboli detected by transcranial Doppler in patients with ICAS compared with aspirin alone [22], and aggressive statin and antihypertensive therapy may decrease the risk of artery-to-artery embolism by stabilizing atherosclerotic plaque in extracranial carotid plaques [23, 24].

Internal border-zone infarcts, which have been associated with hypoperfusion, did not correlate with the absence of collaterals as assessed by ASTIN/SIR grades in this study. Conversely, border-zone infarcts were more frequently present among patients with any grade of collaterals than in those with no collaterals (table 1). One other study has also failed to demonstrate a clear association between border-zone infarcts and impaired collateralization via the circle of Willis [25].

We also found that a majority of mixed patterns in the anterior circulation included infarcts in distal cortical areas together with lesions in the border-zone region, especially the cortical one. This finding supports the hypothesis that a combined embolism-hypoperfusion mechanism may be responsible for these multiple infarcts involving a border-zone region [11]. Support for this is provided by data from an animal model of embolic stroke [26]. Another study has also shown that border-zone infarcts, especially those in the cortical border zone, usually co-occur with infarcts in other locations [27]. Of interest, isolated internal border-zone infarcts were more frequently associated with MCA lesions than with ICAS in our study, supporting the findings in other studies that internal border-zone infarcts are more frequent with MCA stenosis than with extracranial ICAS $[9,28]$. Internal border-zone infarcts in patients with MCA stenosis have been associated with neurological worsening in a recent study [29].

A third mechanism of stroke in intracranial atherosclerosis is perforator occlusive disease as the atherosclerotic plaque can protrude into the orifice of perforators and occlude the lumen, causing a subcortical infarct [30]. We found this pattern represented more often in the posterior circulation, especially in basilar stenosis, and it was not associated with the severity of stenosis (table 1). Highresolution MR studies have shown that atherosclerotic plaques in the basilar artery can lead to paramedian and small deep pontine infarctions, regardless of the severity of stenosis of the parent vessel [31]. 
This study has some significant limitations: infarct patterns on structural brain imaging can only be used to infer and not to prove the mechanism of stroke. Examinations using functional imaging (flow studies, collateral perfusion and embolus detection) were not performed in this study and could add important data when establishing specific stroke mechanisms. Furthermore, the results may not be extrapolated to all patients with ICAS as our study population was derived from a clinical trial (e.g., patients with large disabling infarcts were excluded from the trial). Also, not all the participants had undergone DWI MRI. Finally, the inherent limitations of a post hoc analysis have to be mentioned.

Despite these limitations, this study provides unique data on the relationships between infarct patterns on brain imaging, angiographic features and likely mecha- nisms of stroke in a large cohort of patients with ICAS. Further research is important to accurately establish the specific mechanisms of stroke in patients with ICAS, since preliminary data suggest that the underlying mechanism of stroke is an important determinant of prognosis [4] and it is likely that, in future trials, the entrance criteria for ICAS will be based on the underlying pathophysiologic mechanism of the presenting stroke.

\section{Acknowledgements}

The WASID trial was funded by a research grant (1R01 NS36643; principal investigator: M.I.C.) from the US Public Health Service, National Institute of Neurological Disorders and Stroke (NINDS).

\section{References}

1 Bogousslavsky J, Barnett HJ, Fox AJ, Hachinski VC, Taylor W: Atherosclerotic disease of the middle cerebral artery. Stroke 1986;17: $1112-1120$

2 Wong KS, Gao S, Chan YL, Hansberg T, Lam WW, Droste DW, et al: Mechanisms of acute cerebral infarctions in patients with middle cerebral artery stenosis: a diffusion-weighted imaging and microemboli monitoring study. Ann Neurol 2002;52:74-81.

3 Lee DK, Kim JS, Kwon SU, Yoo SH, Kang DW: Lesion patterns and stroke mechanism in atherosclerotic middle cerebral artery disease: early diffusion-weighted imaging study. Stroke 2005;36:2583-2588.

4 Fiorella D, Derdeyn CP, Lynn MJ, Barnwell SL, Hoh BL, Levy EI, et al: Detailed analysis of periprocedural strokes in patients undergoing intracranial stenting in Stenting and Aggressive Medical Management for Preventing Recurrent Stroke in Intracranial Stenosis (SAMMPRIS). Stroke 2012;43:2682-2688.

5 Bang OY, Lee PH, Heo KG, Joo US, Yoon SR, Kim SY: Specific DWI lesion patterns predict prognosis after acute ischaemic stroke within the MCA territory. J Neurol Neurosurg Psychiatry 2005;76:1222-1228.

6 Jung JM, Kang DW, Yu KH, Koo JS, Lee JH, Park JM, et al: Predictors of recurrent stroke in patients with symptomatic intracranial arterial stenosis. Stroke 2012;43:2785-2787.

7 Kang DW, Chalela JA, Ezzeddine MA, Warach S: Association of ischemic lesion patterns on early diffusion-weighted imaging with TOAST stroke subtypes. Arch Neurol 2003;60:1730-1734.

8 Jung JM, Kwon SU, Lee JH, Kang DW: Difference in infarct volume and patterns between cardioembolism and internal carotid artery disease: focus on the degree of cardioembolic risk and carotid stenosis. Cerebrovasc Dis 17 Tatu L, Moulin T, Bogousslavsky J, Duvernoy 2010;29:490-496.

$>9$ Lee PH, Oh SH, Bang OY, Joo SY, Joo IS, Huh $\mathrm{K}$ : Infarct patterns in atherosclerotic middle cerebral artery versus internal carotid artery disease. Neurology 2004;62:1291-1296.

10 Wessels T, Wessels C, Ellsiepen A, Reuter I, Trittmacher S, Stolz E, et al: Contribution of diffusion-weighted imaging in determination of stroke etiology. AJNR Am J Neuroradiol 2006;27:35-39.

11 Caplan LR, Hennerici M: Impaired clearance of emboli (washout) is an important link between hypoperfusion, embolism, and ischemic stroke. Arch Neurol 1998;55:14751482.

12 Chimowitz MI, Lynn MJ, Howlett-Smith H, Stern BJ, Hertzberg VS, Frankel MR, et al: Comparison of warfarin and aspirin for symptomatic intracranial arterial stenosis. N Engl J Med 2005;352:1305-1316.

13 Warfarin-Aspirin Symptomatic Intracranial Disease (WASID) Trial Investigators: Design, progress and challenges of a double-blind trial of warfarin versus aspirin for symptomatic intracranial arterial stenosis. Neuroepidemiology 2003;22:106-117.

14 Samuels OB, Joseph GJ, Lynn MJ, Smith HA, Chimowitz MI: A standardized method for measuring intracranial arterial stenosis. AJNR Am J Neuroradiol 2000;21:643-646.

15 Liebeskind DS, Cotsonis GA, Saver JL, Lynn MJ, Turan TN, Cloft HJ, et al: Collaterals dramatically alter stroke risk in intracranial atherosclerosis. Ann Neurol 2011;69:963-974.

-16 Higashida RT, Furlan AJ, Roberts H, Tomsick $\mathrm{T}$, Connors B, Barr J, et al: Trial design and reporting standards for intra-arterial cerebral thrombolysis for acute ischemic stroke. Stroke 2003;34:e109-e137.
$\mathrm{H}$ : Arterial territories of the human brain: cerebral hemispheres. Neurology 1998;50: 1699-1708.

18 Tatu L, Moulin T, Bogousslavsky J, Duvernoy $\mathrm{H}$ : Arterial territories of human brain: brainstem and cerebellum. Neurology 1996;47: 1125-1135.

19 Roh JK, Kang DW, Lee SH, Yoon BW, Chang $\mathrm{KH}$ : Significance of acute multiple brain infarction on diffusion-weighted imaging. Stroke 2000;31:688-694.

20 Koch S, Amir M, Rabinstein AA, Reyes-Iglesias Y, Romano JG, Forteza A: Diffusionweighted magnetic resonance imaging in symptomatic vertebrobasilar atherosclerosis and dissection. Arch Neurol 2005;62:12281231.

21 Derdeyn CP, Chimowitz MI, Lynn MJ, et al; Stenting and Aggressive Medical Management for Preventing Recurrent Stroke in Intracranial Stenosis Trial Investigators: Aggressive medical treatment with or without stenting in high-risk patients with intracranial arterial stenosis (SAMMPRIS): the final results of a randomized trial. Lancet 2014;383: 333-341.

22 Wong KS, Chen C, Fu J, Chang HM, Suwanwela NC, Huang YN, et al: Clopidogrel plus aspirin versus aspirin alone for reducing embolisation in patients with acute symptomatic cerebral or carotid artery stenosis (CLAIR study): a randomised, open-label, blindedendpoint trial. Lancet Neurol 2010;9:489_ 497.

23 Spence JD, Coates V, Li H, Tamayo A, Munoz C, Hackam DG, et al: Effects of intensive medical therapy on microemboli and cardiovascular risk in asymptomatic carotid stenosis. Arch Neurol 2010;67:180-186. 
24 Della-Morte D, Moussa I, Elkind MS, Sacco RL, Rundek T: The short-term effect of atorvastatin on carotid plaque morphology assessed by computer-assisted gray-scale densitometry: a pilot study. Neurol Res 2011;33: 991-994.

25 Forster A, Szabo K, Hennerici MG: Pathophysiological concepts of stroke in hemodynamic risk zones: do hypoperfusion and embolism interact? Nat Clin Pract Neurol 2008; 4:216-225.

26 Maki T, Wakita H, Mase M, Itagaki I, Saito N, Ono F, et al: Watershed infarcts in a multiple microembolic model of monkey. Neurosci Lett 2011;499:80-83.
27 Yong SW, Bang OY, Lee PH, Li WY: Internal and cortical border-zone infarction: clinical and diffusion-weighted imaging features. Stroke 2006;37:841-846.

28 Bang OY, Lee PH, Yoon SR, Lee MA, Joo IS, Huh K: Inflammatory markers, rather than conventional risk factors, are different between carotid and MCA atherosclerosis. J Neurol Neurosurg Psychiatry 2005;76:11281134.
29 Tamura A, Yamamoto Y, Nagakane Y, Takezawa H, Koizumi T, Makita N, Makino $\mathrm{M}$ : The relationship between neurological worsening and lesion patterns in patients with acute middle cerebral artery stenosis. Cerebrovasc Dis 2013;35:268-275.

30 Caplan LR: Intracranial branch atheromatous disease: a neglected, understudied, and underused concept. Neurology 1989;39: 1246-1250.

31 Klein IF, Lavallee PC, Mazighi M, SchoumanClaeys E, Labreuche J, Amarenco P: Basilar artery atherosclerotic plaques in paramedian and lacunar pontine infarctions: a high-resolution MRI study. Stroke 2010;41:1405-1409. 